\title{
National and subnational prevalence and burden of glaucoma in China: A systematic analysis
}

Peige Song ${ }^{1}$, Jiawen Wang'ㄹ, Kajo Bucan ${ }^{3}$, Evropi Theodoratou ${ }^{1}$, Igor Rudan ${ }^{1 *}$, Kit Yee Chan $^{1 *}$; on behalf of the Global Health Epidemiology Research Group (GHERG)

\section{${ }^{1}$ Centre for Global Health Research, Usher Institute of Population Health Sciences and Informatics, University of Edinburgh, Edinburgh, Scotland, UK \\ ${ }^{2}$ Institute of Medical Humanities, Peking University, Beijing, China ${ }^{3}$ Department of Ophthalmology, University of Split Hospital Centre, Split, Croatia \\ * Joint last authors}

\section{Correspondence to:} Peige Song Centre for Global Health Research

Usher Institute of Population Health Sciences and Informatics University of Edinburgh Edinburgh EH8 9AG

Scotland, UK

p.song@sms.ed.ac.uk
Background Glaucoma, the second leading cause of blindness, affects approximately 64.3 million individuals worldwide. In China, demographic ageing is in rapid progress. Yet detailed and up-to-date estimates of the scale of glaucoma are rare. We aimed to quantify and understand the prevalence and burden of glaucoma in China from 1990 to 2015, with projections until 2050.

Methods For this systematic review and meta-analysis, we searched China National Knowledge Infrastructure (CNKI), Wanfang, Chinese Biomedicine Literature Database (CBM-SinoMed), PubMed, Embase and Medline using comprehensive search strategies to identify all relevant articles that have reported the prevalence of glaucoma in the general Chinese population. We used a multilevel mixed-effect metaregression to estimate the prevalence rates of primary open-angle glaucoma (POAG) and primary angle-closure glaucoma (PACG), and a random-effects meta-analysis to pool the overall prevalence of secondary glaucoma. United Nations population data were used to estimate and project the number of people with glaucoma from 1990 to 2050. Univariable and multivariable meta-regressions were conducted to assess the association between the prevalence of POAG and PACG and relevant demographic and geographic factors. The national burden of POAG and PACG in the years 2000 and 2010 were distributed to six geographic regions accordingly.

Results From 1990 to 2015, the prevalence of all glaucoma ranged from 2.59\% (95\% $\mathrm{CI}=1.96-3.49)$ to $2.58 \%(95 \% \mathrm{CI}=1.94-3.47)$. For different subtypes of glaucoma, the overall prevalence of POAG ranged from $1.03 \%(95 \% \mathrm{CI}=0.67-1.58)$ in 1990 to $1.02 \%(95 \% \mathrm{CI}=0.67-1.57)$ in 2015 , PACG from $1.41 \%(95 \% \mathrm{CI}=1.18-1.68)$ to $1.40 \%(95 \% \mathrm{CI}=1.17-1.68)$. The overall prevalence of secondary glaucoma was $0.15 \%(95 \% \mathrm{CI}=0.10-0.23)$ during this period. The number of people with all glaucoma in China was 5.92 million (95\% CI=4.47-7.97) in 1990, and 13.12 million (95\% CI =9.88-17.68) in 2015. This increasing trend was also witnessed in different subtypes of glaucoma. The number of people affected by POAG increased from 2.35 million ( $95 \% \mathrm{CI}=1.54-3.60)$ in 1990 to 5.22 million ( $95 \% \mathrm{CI}=3.40-7.98)$ in 2015, PACG from 3.22 million ( $95 \% \mathrm{CI}=2.70-3.84$ ) to 7.14 million (95\% CI=5.97-8.53), and secondary glaucoma from 0.34 million $(95 \% \mathrm{CI}=0.23-0.53)$ to 0.76 million (95\% CI $=0.51-1.17)$. In 2015, more than half (54.42\%) of the glaucoma cases were PACG, followed by POAG (39.79\%) and secondary glaucoma (5.79\%). By 2050, the number of all glaucoma cases in China will be 25.16 million ( $95 \% \mathrm{CI}=18.96-33.86$ ). In the multivariable meta-regressions, the odds ratio (OR) for each decade's increase in age was 1.43 (95\% CI=1.33-1.55) for POAG, and 1.65 (95\% CI $=1.51-1.80)$ for PACG; males were more likely to have POAG (OR 1.36, 95\% CI=1.17-1.59), but less likely to have PACG (OR 0.53, 95\% CI=0.46-0.60) compared with females. After adjustment of age and gender, people living in urban areas were more likely to have POAG compared with those in rural areas (OR 1.54, 95\% CI=1.02-2.35). People in Northeast China were at a higher risk (OR 1.77, 95\% CI=1.07-2.94) of having PACG than people in East China. Among the six regions, East China owed the most POAG and PACG cases, whereas Northwest China owed the least.

Conclusions This systematic review and meta-analysis suggests a substantial burden of glaucoma in China, with great variances among the different age groups, genders, settings and geographic regions. With the dramatic ageing trend in the next three decades, the prevalence and burden of glaucoma will continue to increase. More elaborate epidemiological studies are needed to optimise public health strategies for mitigating this important health problem. 
Glaucoma, the second leading cause of blindness, is an optic neuropathy characterised by progressive structural and functional changes of the optic nerve, leading to a typical appearance of the optic disc and visual field damage if untreated [1-5]. People with glaucoma-induced visual impairment generally suffer from decreased vision-related quality of life (including reduced vision-dependent mobility, increased incidence of falls), and place a huge burden on caregivers and communities [6-9]. Glaucoma is often associated with a long and asymptomatic initial phase, and is usually unnoticed until its later stages, when extensive and irreversible damage has occurred $[10,11]$. In the late stage of the disease, the effects of medical and surgical treatment can be unsatisfactory, underscoring the importance of early detection and treatment $[1,2,12]$. As glaucoma has an uncertain prognosis, it requires lifelong management and follow-up to prevent further loss of vision $[1,13,14]$. The recognition of glaucoma's pervasive nature and adverse impact on both individuals and society, and the documentation of the magnitude and distribution of glaucoma is of pronounced importance to inform clinicians and researchers, and will guide policymakers in health services allocation $[9,15,16]$.

Globally, 64.3 million individuals, or 3.5\% of the world's population, have glaucoma; of these, about 5.7 million people are visually impaired and 3.1 million are blind $[5,16]$. Of the many subtypes of glaucoma, primary open-angle glaucoma (POAG) is the most common in nearly all regions, accounting for more than two-thirds $(68.6 \%)$ of all glaucoma cases $[15,16]$. Geographically, POAG is believed to be particularly prevalent in Africa (4.2\%), and least prevalent in Asia (2.3\%); however, more than half (53.4\%) of the global POAG cases are in Asia due to the relatively large population size of this region $[16,17]$. Compared with POAG, primary angle-closure glaucoma (PACG) is a less common subtype, but is more visually damaging [18]. PACG also disproportionally affects the global population; it is least common in North America (0.3\%), but is the predominant type of glaucoma in Asian populations (1.1\%) [16]. More than three quarters $(76.7 \%)$ of the global PACG cases are in Asia [16,17]. Given the positive association of glaucoma prevalence and advanced age, glaucoma is expected to become an even larger public health concern in the coming decades [18-20]. This dramatic increase of glaucoma burden is also expected to be the case for the largest developing country - China - where rapid ageing of the population is under way [21-23].

The last three decades have seen a proliferation of population-based studies in China. The mounting volume of data on the prevalence of glaucoma in Chinese bibliographical databases allows us to explore the burden of glaucoma in China from a modelling approach [24-26]. However, epidemiological studies on glaucoma to date have been restricted to specific demographic and geographic features in China, and are therefore not generalisable to the overall Chinese population [27-30]. Because of the uncertainty and variation surrounding the epidemiological surveys on glaucoma, a systematic synthesis of the prevalence of glaucoma in China is particularly needed. The first study to pool the prevalence of primary glaucoma in China was published in 2013, which revealed an overall prevalence of $0.7 \%$ for POAG, and $1.4 \%$ for PACG [30]. The meta-analysis was based on 14 articles from 12 population-based studies published before 2009. No study has yet systematically appraised research into the prevalence of primary glaucoma in China published over the last nine years. Furthermore, considering that different subtypes of glaucoma may require different strategies for screening, prevention and treatment, there is a pressing need for a more updated effort to provide finer quantification of the relative magnitude across the main types of glaucoma, namely, POAG, PACG and secondary glaucoma, which is missing in the 2013 study [17].

To fill the gaps in the evidence matrix, in this study we used a comprehensive systematic review to synthesise the best available evidence from 1990 onwards. Based on the retained evidence, we assessed the prevalence and burden of glaucoma and its subtypes at both the national and subnational levels. The aims of this present study were: 1) to estimate glaucoma prevalence in China by using epidemiological modelling; 2) to estimate and project the overall prevalence and number of people with glaucoma at the national level from 1990 to 2050; and 3) to estimate the regional prevalence and number of people with glaucoma from 2000 to 2010.

\section{METHODS}

\section{Systematic review}

Our comprehensive systematic review was conducted and reported in line with the Preferred Reporting Items for Systematic reviews and Meta-Analyses (PRISMA) guidelines and the Guidelines for Accurate and Transparent Health Estimates Reporting (GATHER) statement [31,32]. 


\section{Search strategy}

A systematic literature search was performed to identify all relevant articles that have reported the prevalence of glaucoma in the general Chinese population. The searched databases included three Chinese and three English electronic databases: China National Knowledge Infrastructure (CNKI), Wanfang, Chinese Biomedicine Literature Database (CBM-SinoMed), PubMed, Embase, and Medline. The search strategy combined controlled vocabularies (eg, Medical Subject Heading terms) and free text terms of prevalence (prevalence, incidence, mortality, morbidity, epidemiology), glaucoma and China (China, Chinese, Hong Kong, Macau, Taiwan); the specific search strategies for each database were adapted to fit their specific features (Table S1 in Online Supplementary Document). We restricted our searches to studies that were published between January 1990 and August 2017. No language restrictions were applied to the searches or search results. The reference lists of all included full-text articles were also scrutinised in detail to identify additional data sources.

\section{Inclusion and exclusion criteria}

The inclusion and exclusion criteria adopted in this study were developed based on the examination guidelines for glaucoma-related population-based studies [3,16,33]. To be included in this systematic review, studies had to be population-based and report the prevalence of glaucoma. We excluded studies that were hospital-based or conducted in a population that was not representative of the general population. Reviews, commentaries, studies that only adopted qualitative methods and studies that reported the number of eyes with glaucoma instead of the number of individuals were also excluded because they were not able to provide numerical estimates of glaucoma prevalence. Studies that did not include clear assessment methods of glaucoma or relied on self-reported diagnosis were also excluded. Although different case definitions and examination methods exist in identifying glaucoma cases, a remarkable similarity of glaucoma prevalence was noted across surveys despite variations in survey methodology and glaucoma definition [16,34-36]. In this systematic review, we did not exclude studies on the basis of their specific definitions of glaucoma or adopted instrumentation; the assessment of glaucoma should be independent of intraocular pressure (IOP) measurements, but rely on structural or functional evidence of glaucomatous optic neuropathy evaluated by optic disc evaluation or visual field testing $[3,16]$. Therefore, studies were eligible to contribute data if the following standardised assessments were carried out in suspected cases of glaucoma: anterior chamber angle/depth evaluation by slit-lamp examination or gonioscopy, optic disc evaluation by ophthalmologists using slit-lamp biomicroscopy or fundus photography and visual field testing with automated static perimetry.

\section{Study selection and data extraction}

Search results from the six bibliographic databases were merged together and duplicate references were removed within and between the databases. All records were independently screened by two researchers (PS and JW) in two stages: screening of titles and abstracts, followed by the retrieval and screening of full-text articles. For multiple articles that reported results of the same individual study, those with the most comprehensive or most recent data were kept. Disagreements were resolved by consensus through discussion.

For the purpose of this study, glaucoma was classified into three main types: POAG, PACG and secondary glaucoma. Relevant data on different subtypes of glaucoma were separately extracted from the studies included. The pilot tested and refined extraction table included three modules:

1) Characteristics of the study: author(s), publication year, study setting (urban, rural or mixed), study location, geographic region, survey year, sampling method, study design (cross-sectional or cohort), whether anterior chamber angle/depth evaluation, IOP measurement, optic disc evaluation and visual field testing were conducted;

2) Characteristics of the investigated population: number of the sample, gender (male, female or mixed), and age (age range, mean or median age, or midpoint of the age range);

3) Prevalence estimates: the number of participants who had been tested and the number of people with glaucoma, by age group, gender, setting and glaucoma subtype, where available.

We classified the sites where the studies were conducted into six geographic regions following definitions of National Bureau of Statistics of China: East China, North China, Northeast China, Northwest China, South Central China, and Southwest China (Table 1) [37,38]. Missing data on survey years were imputed for two studies by subtracting three years from the published year, which was based on the average 
Table 1. The six geographic regions in China

Retion InGLUDED PROVINCES

North China

Beijing Municipality, Hebei province, Inner Mongolia Autonomous Region, Shanxi province, Tianjin Municipality;

Northeast China

Heilongjiang province, Jilin province, Liaoning province;

East China

Anhui province, Fujian province, Jiangsu province, Jiangxi province, Shandong province, Shanghai Municipality, Zhejiang province;

South Central China

Southwest China

Guangdong province, Guangxi Zhuang Autonomous Region, Hainan province, Henan province, Hubei province, Hunan province;

Northwest China Chongqing Municipality, Guizhou province, Sichuan province, Tibet Autonomous Region, Yunnan province;

Gansu province, Ningxia Hui Autonomous Region, Qinghai province, Shaanxi province, Xinjiang Uyghur Autonomous Region;

time from survey to publication in studies with available data. In case of censoring age groups, eg, older than 80 years, the same width as other age groups in the same study was used to impute the missing age band.

\section{Statistical analysis}

\section{Epidemiological modelling of glaucoma prevalence}

Prevalence of POAG, PACG and secondary glaucoma was stabilised by using the logit transformation [39]. In this study, random-effects models were used throughout because of significant heterogeneity in the reported prevalence of POAG, PACG and secondary glaucoma between studies (Table S2 in Online Supplementary Document). The overall prevalence of secondary glaucoma was derived from the study-specific estimates using a random-effects meta-analysis model (DerSimonian and Laird method) [40]. For POAG and PACG, one individual study might have contributed multiple outcome measurements in the data extraction stage; to take into account the occurrence of different data points from the same study, a multilevel mixed-effect logistic regression approach was adopted [41,42]. Before constructing epidemiological models of the prevalence for POAG and PACG, the association of prevalence estimates and each individual variable, ie, age, gender (male and female), setting (urban, rural and mixed), geographic region, and survey year, was explored using a univariable meta-regression; this was done for POAG and PACG separately. Age and gender were found to be the only common factors that were significantly associated with prevalence estimates of both POAG and PACG. For the purpose of estimating the national prevalence of POAG and PACG, an age- and gender-adjusted model was developed. Given that:

$$
\text { prevalence }=\mathrm{p}=\frac{\text { glaucoma cases }}{\text { number of participants }}
$$

Then, the prevalence estimates were stabilised by the logit link,

$$
\operatorname{logit}(\mathrm{p})=\ln \left(\frac{p}{1-p}\right)=\ln (\text { odds })=\alpha+\beta_{1}{ }^{*} x_{1}+\beta_{2}{ }^{*} x_{2}+\ldots
$$

The prevalence of glaucoma was established as a function of age and gender:

$$
\operatorname{logit}(\mathrm{p})=\alpha+\beta_{1}{ }^{*} \text { Age }+\beta_{2}{ }^{*} \text { Gender }
$$

Therefore,

$$
\text { odds }=\frac{p}{1-p}=e^{\left(\alpha+\beta_{1}{ }^{*} \text { Age }+\beta_{2}{ }^{*} \text { Gender }\right)}
$$

And,

$$
\text { prevalence }=\mathrm{p}=\frac{e^{\left(\alpha+\beta_{1}{ }^{*} \text { Age }+\beta_{2}{ }^{*} \text { Gender }\right)}}{1+e^{\left(\alpha+\beta_{1}^{*} \text { Age }+\beta_{2}{ }^{*} \text { Gender }\right)}}
$$

Finally, the age- and gender-specific prevalence of POAG and PACG was generated based on the abovementioned model. The lower bound of age range was set as 45 years and the upper bound as 89 years because enough data were available for model construction in this broad age range.

\section{Estimation of national population with glaucoma from 1990 to 2015}

The national number of people with glaucoma (glaucoma "envelopes") from 1990 to 2015 was derived by multiplying the prevalence of glaucoma with the population in China, available from the United Na- 
tions Population Division (UNPD) [43]. For POAG and PACG, the numbers of age- and gender-specific cases were calculated by using their age- and gender-specific prevalence for each 5-year age group estimated in the above models. In view of the limited data availability, the age- and gender-specific prevalence of secondary glaucoma was not estimated, thus the overall prevalence pooled from 12 studies were used (Figure S3 in Online Supplementary Document). This was performed for the years 1990, 2000, 2010 and 2015 consecutively.

\section{Projection of national population with glaucoma from 2020 to 2050}

For our projection of people with glaucoma to the year 2050, the prevalence of POAG, PACG and secondary glaucoma was assumed to be constant over the next 33 years. This assumption was partly supported by our multivariable meta-regression model, where no significant changes of POAG and PACG prevalence with survey year were observed after adjusting the effects of age and gender. Bases on the same procedures adopted in the estimation of national population with glaucoma from 1990 to 2015, the numbers of people with glaucoma from 2020 to 2050 were projected by taking UNDP Prospects data, which took into account mortality rates and fertility rates in its population projection [43].

\section{Effects of demographic and geographic factors on the prevalence of POAG and PACG}

To investigate whether the prevalence of POAG and PACG varied across different subgroups of the population, the associations of prevalence estimates and variables of interest were assessed by multivariable metaregression, adjusting the effects of age and gender. Before model fitting, all variables were tested for correlation to avoid multicollinearity. The variables were selected based on our knowledge, previous studies and the availability of data in this present study, which included setting (urban, rural and mixed), geographic region, and survey year. As a rule, at least seven data points should be available for each variable [44].

\section{Estimation of regional population with POAG and PACG from 2000 to 2010}

The regional population with glaucoma was estimated at an envelope condition. This method was initially proposed by the Child Health Epidemiology Reference Group (CHERG) and has been widely adopted in disease burden research [45-47]. The national glaucoma cases were set as the glaucoma envelope, for POAG and PACG separately. Then the "POAG envelope" and the "PACG envelope" were split into the six subnational regions according to the different distributions of risk factors identified in the multivariable meta-regression models. This was conducted for the years 2000 and 2010, where regional population data were available from the fifth and sixth censuses of China $[37,38]$.

All analyses were performed using R, version 3.3.0 (R Foundation for Statistical Computing, Vienna, Austria). The China base map was obtained as a shapefile from the Global Administrative Areas (GADM) database (GADM, 2015, version 2.0; www.gadm.org) and all maps were drawn by ArcMap version 10.1 (Environmental Systems Research Institute, Redlands, CA). A two-sided p-value of less than 0.05 indicated statistically significant difference for all analyses.

\section{RESULTS}

\section{Summary of systematic review}

Our initial search identified a total of 10609 citations for screening, after elimination of duplicates, 5387 records remained. After screening titles and abstracts, 623 potentially relevant full-text articles were reviewed for eligibility, of which 30 reported the prevalence of glaucoma and were included in the systematic review (Figure 1). A full list of the included studies is shown in Table S3 in Online Supplementary Document.

The 30 studies, published between 1995 and 2016, reported the prevalence of glaucoma with a geographical distribution covering all the six regions in China (Figure 2). The included studies were all crosssectional, of which 20 studies reported the prevalence of POAG, 25 focused on PACG and 12 on secondary glaucoma. The detailed characteristics of every study are listed in Table S4 in Online Supplementary Document, and the main characteristics of the 30 studies are summarised in Table 2. More than half of the 30 studies were published in the past seven years, underlining the necessity for conducting our revision of the estimate. The included studies were generally larger, with the majority (60\%, $\mathrm{n}=18$ ) being conducted in rural areas. Anterior chamber angle/depth evaluation, IOP measurement and 


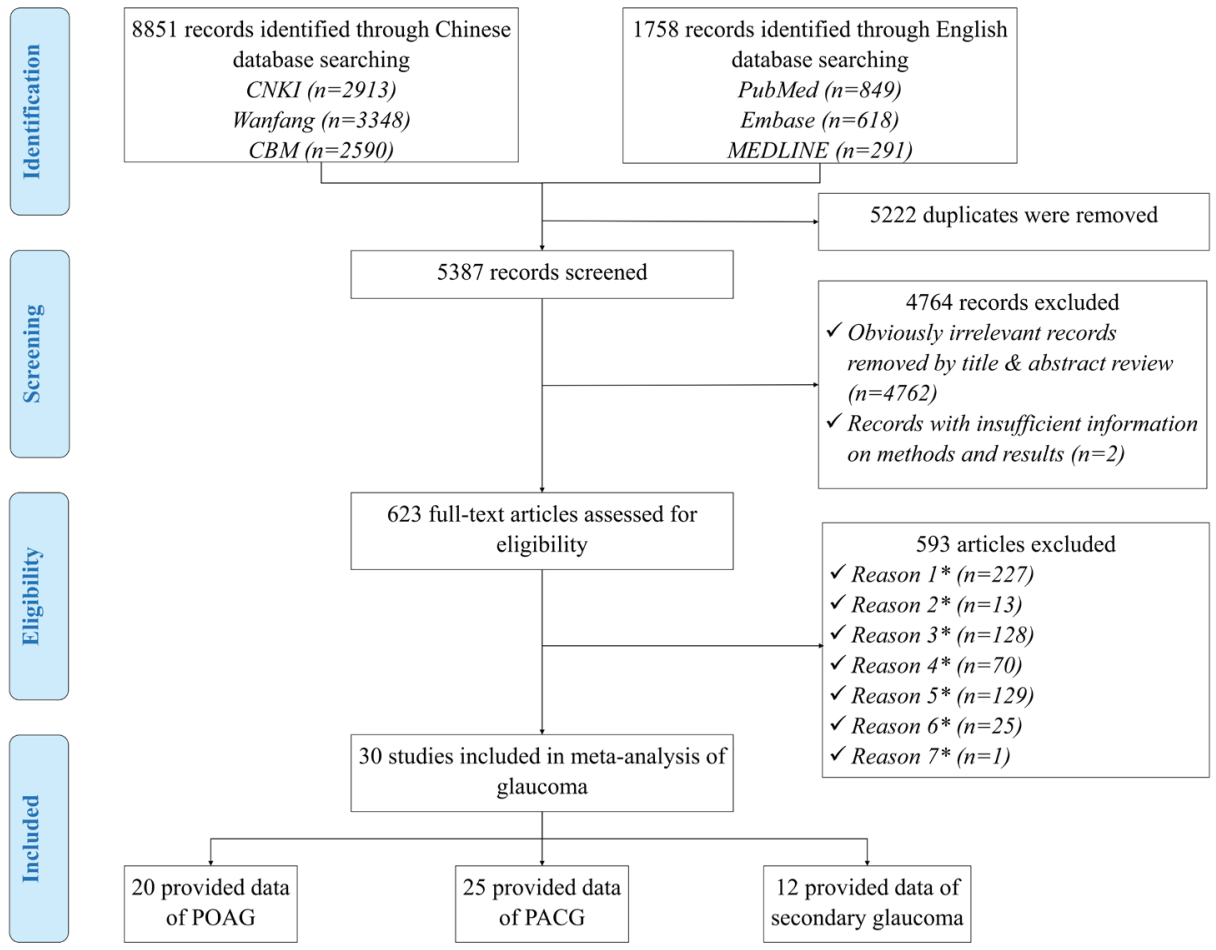

Figure 1. Systematic review flow diagram of studies on glaucoma prevalence in China. Note: *Reason 1-Studies that were not population-based; *Reason 2-Studies that were not based in China; *Reason 3-Papers with no numerical prevalence measure of glaucoma; *Reason 4-Studies that relied on self-reported diagnoses or didn't conduct standardised assessments (anterior chamber angle/depth evaluation by slit-lamp examination or gonioscopy, optic disc evaluation by ophthalmologists using slit-lamp biomicroscopy or fundus photography and visual field testing with automated static perimetry) in at least glaucoma suspects; *Reason 5-Studies that were conducted in a population with unrepresentative characteristics (diabetic patients, people with reduced vision, etc.); *Reason 6-Multiple publications of the same study; *Reason 7-Papers with inconsistency between reported methods and presented results.

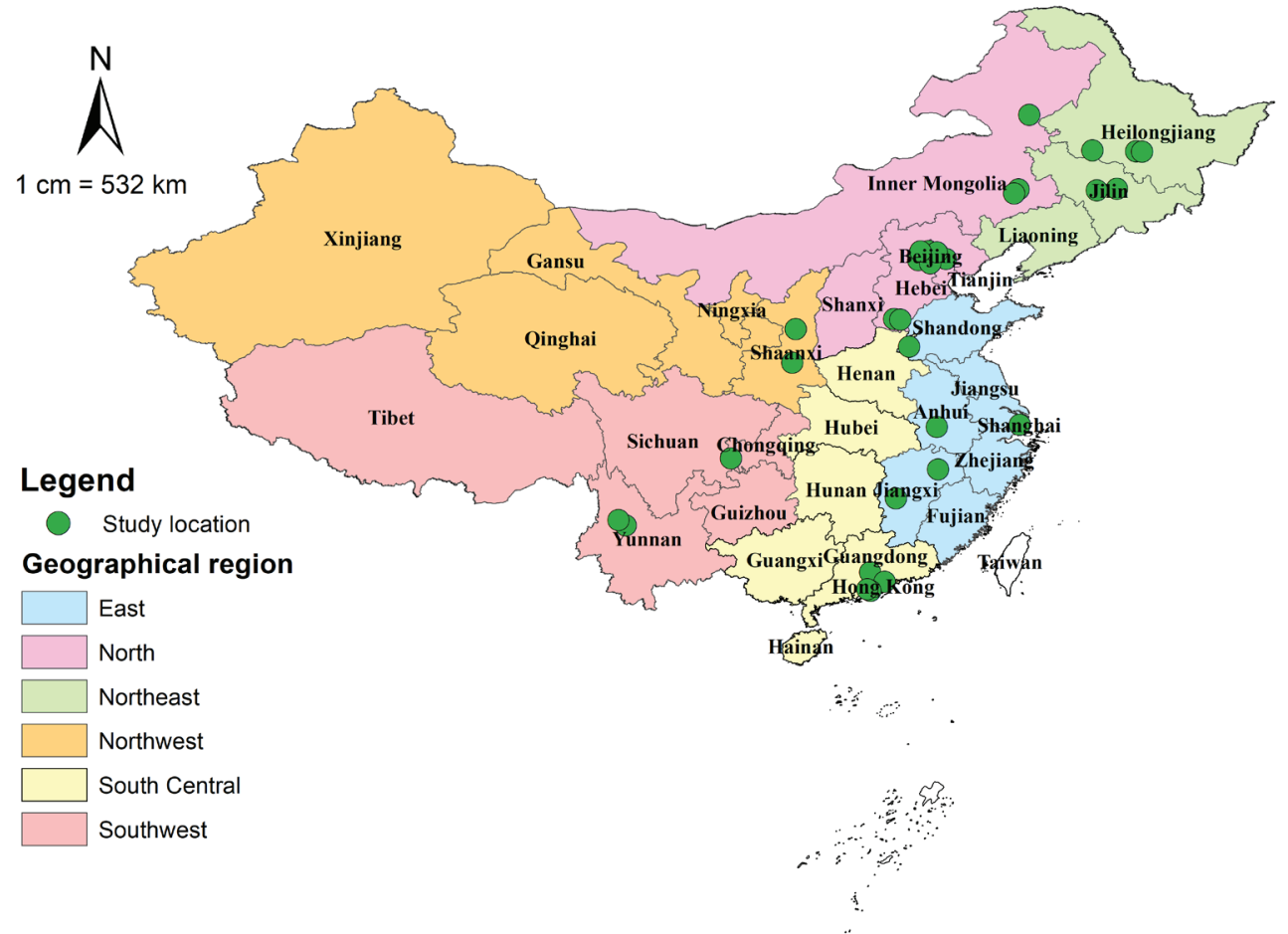

Figure 2. Geographical distribution of the included studies on glaucoma prevalence in China $(\mathrm{n}=30)$. 
Table 2. Main characteristics of the included studies on glaucoma prevalence in China $(n=30)$

\begin{tabular}{|c|c|}
\hline Characteristics of study & $\begin{array}{l}\text { NuMBER OF } \\
\text { STUDIES (\%) }\end{array}$ \\
\hline \multicolumn{2}{|l|}{ Year published: } \\
\hline 1990-1999 & $2(6.7)$ \\
\hline 2000-2009 & $12(40.0)$ \\
\hline 2010-2017 & $16(53.3)$ \\
\hline \multicolumn{2}{|l|}{ Setting: } \\
\hline Urban & $6(20.0)$ \\
\hline Rural & $18(60.0)$ \\
\hline Mixed & $6(20.0)$ \\
\hline \multicolumn{2}{|l|}{ Sample size: } \\
\hline $500-1500$ & $6(20.0)$ \\
\hline $1501-2500$ & $7(23.3)$ \\
\hline $2501-5000$ & $9(30.0)$ \\
\hline$>5000$ & $8(26.7)$ \\
\hline \multicolumn{2}{|l|}{ Geographic regions: } \\
\hline North China & $12(40.0)$ \\
\hline Northeast China & $5(16.7)$ \\
\hline East China & $4(13.3)$ \\
\hline South Central China & $4(13.3)$ \\
\hline Southwest China & $3(10.0)$ \\
\hline Northwest China & $2(6.7)$ \\
\hline \multicolumn{2}{|c|}{ Anterior chamber angle/depth evaluation: } \\
\hline In all participants & $28(93.3)$ \\
\hline In glaucoma suspects & $2(6.7)$ \\
\hline \multicolumn{2}{|l|}{ IOP measurement: } \\
\hline In all participants & $29(96.7)$ \\
\hline In glaucoma suspects & $1(3.3)$ \\
\hline \multicolumn{2}{|l|}{ Optic disc evaluation: } \\
\hline In all participants & $28(93.3)$ \\
\hline In glaucoma suspects & $2(6.7)$ \\
\hline \multicolumn{2}{|l|}{ Visual field testing: } \\
\hline In all participants & $4(13.3)$ \\
\hline In glaucoma suspects & $26(86.7)$ \\
\hline
\end{tabular}

optic disc evaluation were mostly undertaken in all participants, whereas visual field testing was largely used in glaucoma suspects.

\section{Age- and gender-specific prevalence of POAG and PACG}

Based on a substantial number of data points from the included studies, the gender-specific relationship between age and the prevalence of POAG and PACG was constructed (Figure 3). The informative data points covered a wide age spectrum from the mid-30s to the 9th decade, with the majority concentrating between the mid-40s to the mid-80s. Therefore, in the estimation of age- and gender-specific prevalence of POAG and PACG, the age range was set as from 45 years to 89 years.

Table 3 and Figure 4 show the estimated age- and gender-specific prevalence of POAG and PACG respectively. Generally, the prevalence of POAG and PACG both increased steadily with advanced age, and this positive relationship between age and prevalence rate was similar between genders, but more pronounced for PACG. In males, the prevalence of POAG ranged from $0.74 \%(95 \% \mathrm{CI}=0.48-1.14)$ in individuals aged $45-49$ years to $3.02 \%(95 \% \mathrm{CI}=1.92-4.73)$ in those aged 85-89 years. The prevalence of POAG in females was slightly lower than that in males across the whole age spectrum from 45 to 89 years, ranging from $0.54 \%(95 \% \mathrm{CI}=0.35-0.84)$ to $2.24 \%(95 \% \mathrm{CI}=1.41-$ 3.53). In contrast, the prevalence of PACG was consistently higher in females than in males. In females, the prevalence of PACG ranged from $0.91 \%(95 \% \mathrm{CI}=0.74-1.11)$ in those aged $45-49$ years to $6.33 \%$ (95\% CI $=4.98-8.02)$ in those aged 85-89 years. In males, the prevalence of PACG increased from $0.48 \%(95 \% \mathrm{CI}=0.39-0.60)$ in people aged $45-49$ years to $3.44 \%(95 \% \mathrm{CI}=2.66-4.45)$ in elderly aged 8589 years.
Figure 3. Age- and gender-specific prevalence of primary open-angle glaucoma (POAG) and primary angle-closure glaucoma (PACG) based on the informative data points from the included studies. Note: The size of each bubble is proportional to the sample size. Overall, there were 86 data points for constructing the gender-specific relation between age and prevalence for POAG, and 103 for PACG.
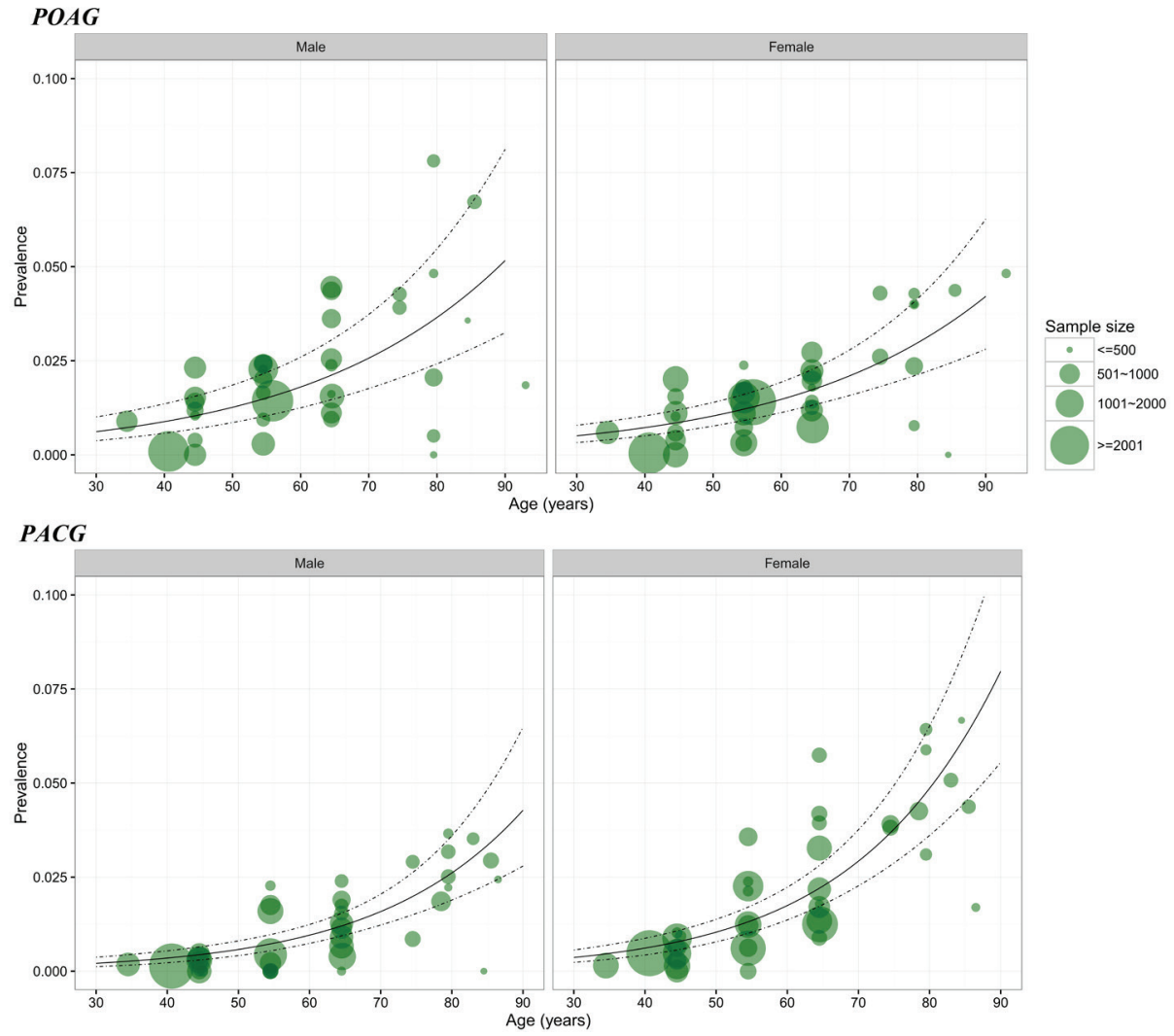
Table 3. Estimated gender-specific prevalence of POAG and PACG in China, by age group

\begin{tabular}{|c|c|c|c|c|}
\hline \multirow[t]{2}{*}{ Age (years) } & \multicolumn{2}{|c|}{ Prevalence of POAG $(\%, 95 \%$ CI) } & \multicolumn{2}{|c|}{ Prevalence of PACG $(\%, 95 \%$ CI) } \\
\hline & Male & Female & Male & Female \\
\hline \multirow[t]{2}{*}{$45-49$} & 0.74 & 0.54 & 0.48 & 0.91 \\
\hline & $(0.48-1.14)$ & $(0.35-0.84)$ & $(0.39-0.60)$ & $(0.74-1.11)$ \\
\hline \multirow[t]{2}{*}{$50-54$} & 0.88 & 0.65 & 0.62 & 1.16 \\
\hline & $(0.57-1.34)$ & $(0.42-0.99)$ & $(0.51-0.75)$ & $(0.98-1.38)$ \\
\hline \multirow[t]{2}{*}{$55-59$} & 1.05 & 0.77 & 0.79 & 1.49 \\
\hline & $(0.69-1.60)$ & $(0.51-1.18)$ & $(0.66-0.94)$ & $(1.28-1.74)$ \\
\hline \multirow[t]{2}{*}{$60-64$} & 1.25 & 0.92 & 1.01 & 1.90 \\
\hline & $(0.83-1.90)$ & $(0.61-1.41)$ & $(0.86-1.20)$ & $(1.65-2.20)$ \\
\hline \multirow[t]{2}{*}{$65-69$} & 1.50 & 1.10 & 1.30 & 2.43 \\
\hline & $(0.98-2.27)$ & $(0.72-1.68)$ & $(1.09-1.54)$ & $(2.10-2.81)$ \\
\hline \multirow[t]{2}{*}{$70-74$} & 1.79 & 1.32 & 1.66 & 3.10 \\
\hline & $(1.17-2.72)$ & $(0.86-2.02)$ & $(1.38-1.99)$ & $(2.64-3.64)$ \\
\hline \multirow[t]{2}{*}{$75-79$} & 2.13 & 1.57 & 2.12 & 3.94 \\
\hline & $(1.38-3.27)$ & $(1.02-2.43)$ & $(1.73-2.59)$ & $(3.28-4.73)$ \\
\hline \multirow[t]{2}{*}{$80-84$} & 2.54 & 1.87 & 2.70 & 5.00 \\
\hline & $(1.63-3.93)$ & $(1.20-2.92)$ & $(2.15-3.39)$ & $(4.06-6.16)$ \\
\hline \multirow[t]{2}{*}{$85-89$} & 3.02 & 2.24 & 3.44 & 6.33 \\
\hline & $(1.92-4.73)$ & $(1.41-3.53)$ & $(2.66-4.45)$ & $(4.98-8.02)$ \\
\hline
\end{tabular}

POAG - primary open-angle glaucoma, PACG - primary angle-closure glaucoma, CI - confidence interval

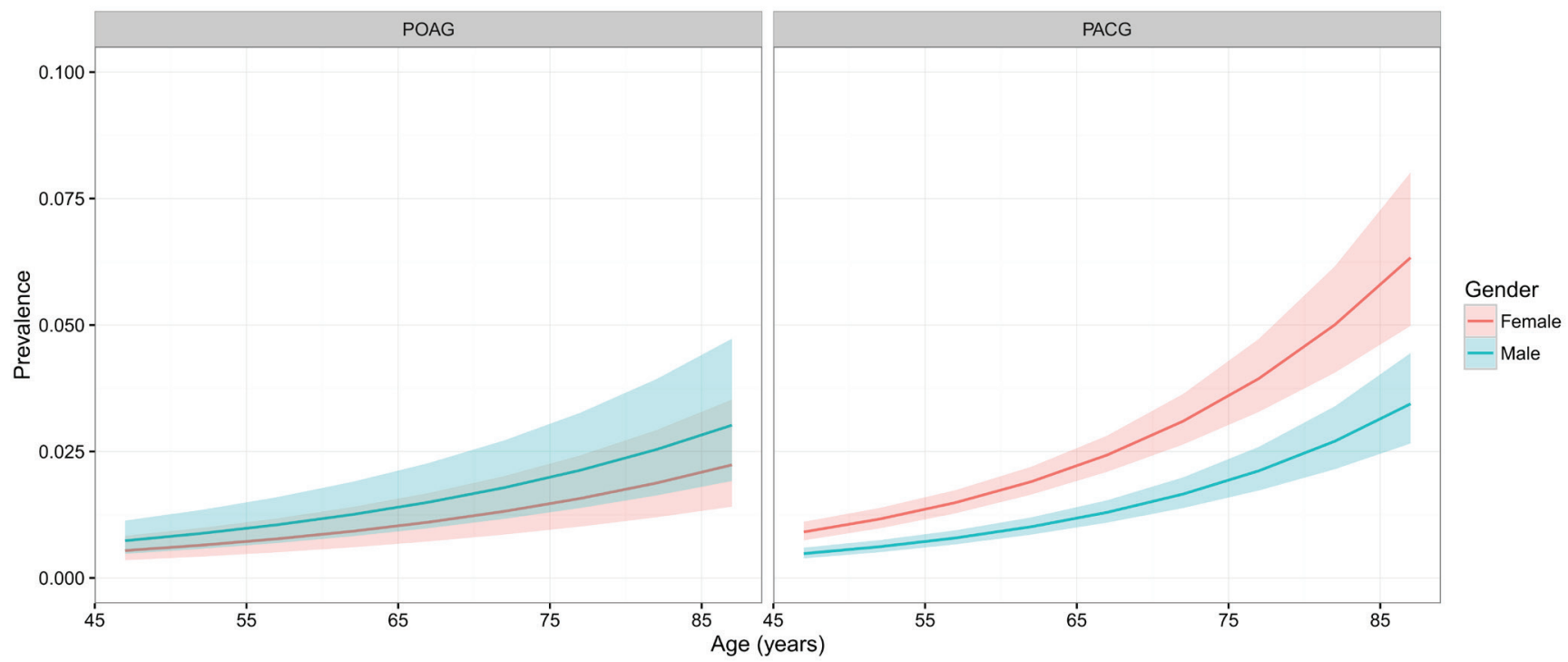

Figure 4. Estimated age- and gender-specific prevalence of primary open-angle glaucoma (POAG) and primary angle-closure glaucoma (PACG) in China, with 95\% confidence intervals.

\section{National population with glaucoma from 1990 to 2015}

By extrapolating the estimated age- and gender-specific prevalence of POAG and PACG to UNPD data, the numbers of people with POAG and PACG were generated (Table S5 in Online Supplementary Document). At the national level, the overall prevalence of glaucoma was listed in Table 4. From 1990 to 2015 , the prevalence of all glaucoma ranged from $2.59 \%(95 \% \mathrm{CI}=1.96-3.49)$ to $2.58 \%(95 \% \mathrm{CI}=1.94-$ 3.47), indicating a slightly relative decreasing rate of $0.39 \%$. For different subtypes of glaucoma, the overall prevalence of POAG ranged from 1.03\% (95\% CI=0.67-1.58) in 1990 to $1.02 \%(95 \% \mathrm{CI}=0.67-1.57)$ in 2015 , which yielded a relative decreasing rate of $0.97 \%$. Similarly, the prevalence of PACG decreased by $0.71 \%$, from $1.41 \%(95 \% \mathrm{CI}=1.18-1.68)$ in 1990 to $1.40 \%(95 \% \mathrm{CI}=1.17-1.68)$ in 2015 . Based on 
Table 4. Estimated prevalence and number of people with glaucoma in China from 1990 to 2015, by glaucoma type

\begin{tabular}{|c|c|c|c|c|c|c|}
\hline \multirow[t]{2}{*}{ Glaucoma tYPE } & \multicolumn{2}{|c|}{$\begin{array}{l}\text { Prevalence of glaucoma } \\
(\%, 95 \% \text { CI })\end{array}$} & \multicolumn{2}{|c|}{$\begin{array}{l}\text { NUMBER OF PEOPLE WITH GLAUCOMA } \\
\text { (MILLON, 95\% CI) }\end{array}$} & \multicolumn{2}{|c|}{$\begin{array}{l}\text { Relative RAIE OF CHANGE } \\
(\%, 1990-2015)\end{array}$} \\
\hline & 1990 & 2015 & 1990 & 2015 & Prevalence & Cases \\
\hline \multirow[t]{2}{*}{ POAG } & 1.03 & 1.02 & 2.35 & 5.22 & -0.97 & 122.13 \\
\hline & $(0.67-1.58)$ & $(0.67-1.57)$ & $(1.54-3.60)$ & $(3.40-7.98)$ & & \\
\hline \multirow[t]{2}{*}{ PACG } & 1.41 & 1.40 & 3.22 & 7.14 & -0.71 & 121.74 \\
\hline & $(1.18-1.68)$ & $(1.17-1.68)$ & $(2.70-3.84)$ & $(5.97-8.53)$ & & \\
\hline \multirow[t]{2}{*}{ Secondary glaucoma } & \multicolumn{2}{|c|}{0.15} & 0.34 & 0.76 & - & 123.53 \\
\hline & \multicolumn{2}{|c|}{$(0.10-0.23)$} & $(0.23-0.53)$ & $(0.51-1.17)$ & & \\
\hline \multirow[t]{2}{*}{ All glaucoma* } & 2.59 & 2.58 & 5.92 & 13.12 & -0.39 & 121.62 \\
\hline & $(1.96-3.49)$ & $(1.94-3.47)$ & $(4.47-7.97)$ & $(9.88-17.68)$ & & \\
\hline
\end{tabular}

POAG - primary open-angle glaucoma, PACG - primary angle-closure glaucoma, CI - confidence interval

*All glaucoma includes POAG, PACG and secondary glaucoma.

12 individual studies, the overall prevalence of secondary glaucoma was pooled as $0.15 \%$ ( $95 \% \mathrm{CI}=0.10$ 0.23 ) and assumed as constant over the time frame of this research (Figure S3 in Online Supplementary Document).

With the ageing of Chinese population during 1990-2015, the total number of people living with glaucoma increased dramatically (Table 4). The number of people with all glaucoma in China was 5.92 million (95\% CI =4.47-7.97) in 1990 and 13.12 million (95\% CI=9.88-17.68) in 2015, indicating an overall increasing rate of $121.62 \%$ throughout this period. This increasing trend was also witnessed in different subtypes of glaucoma. For POAG, the affected cases increased by $122.13 \%$, from 2.35 million (95\% CI $=1.54-3.60)$ in 1990 to 5.22 million $(95 \% \mathrm{CI}=3.40-7.98)$ in 2015 . Similarly, the number of people with PACG increased by $121.74 \%$, ranging from 3.22 million $(95 \% \mathrm{CI}=2.70-3.84)$ in 1990 to 7.14 million ( $95 \% \mathrm{CI}=5.97-8.53$ ) in 2015. Even for secondary glaucoma, whose overall prevalence was assumed as constant, the number of affected people also increased by $123.53 \%$ during 1990 to 2015, from 0.34 million ( $95 \% \mathrm{CI}=0.23-0.53$ ) to 0.76 million ( $95 \% \mathrm{CI}=0.51-1.17$ ). In 2015, more than half (54.42\%) of the glaucoma cases were PACG, followed by POAG $(39.79 \%)$ and secondary glaucoma (5.79\%). From 1990 to 2015, the age group that contributed the most cases shifted from 55-59 years to 60-64 years for both POAG and PACG (Figure 5).

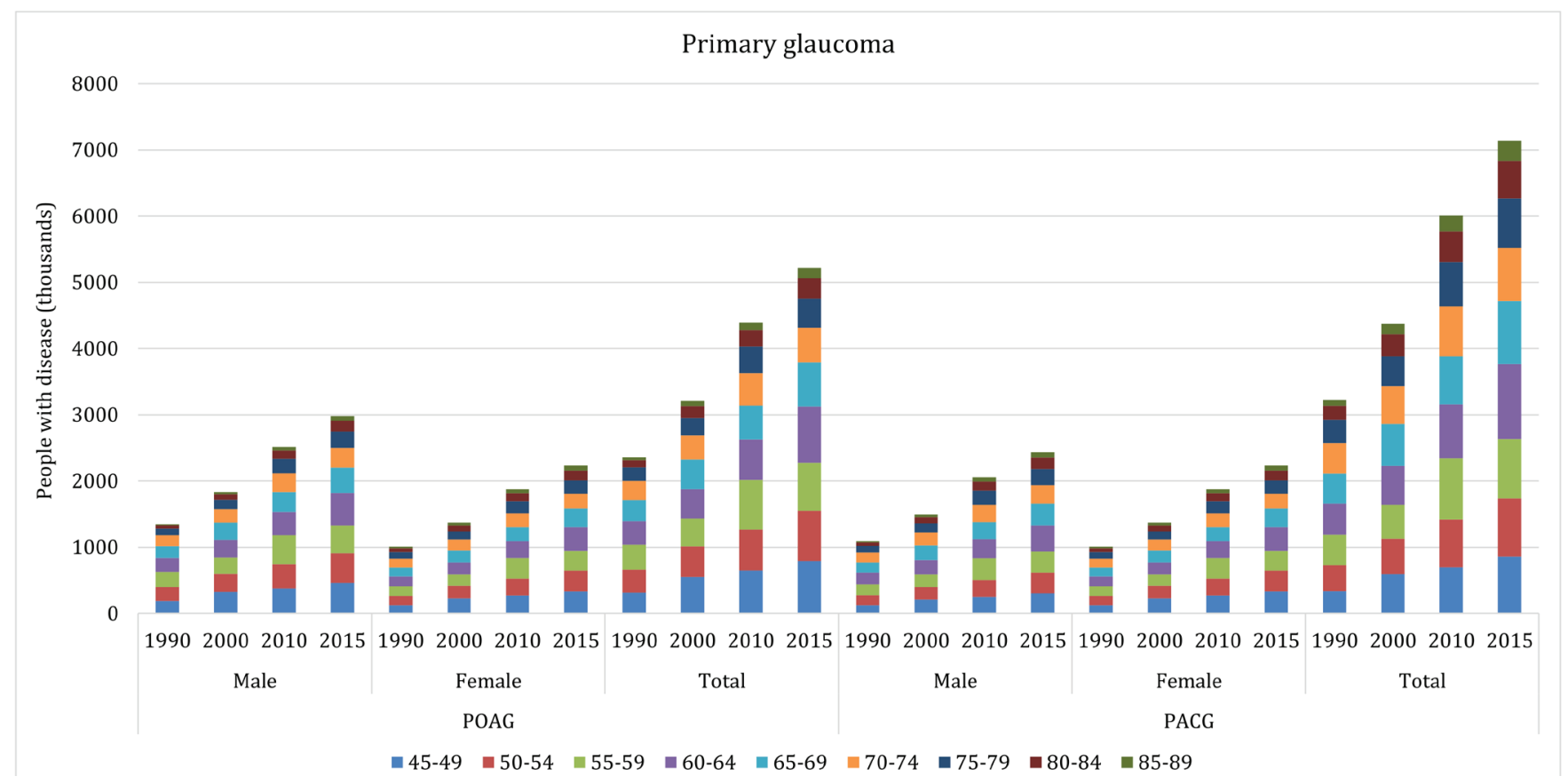

Figure 5. Estimated gender-specific number of people with primary open-angle glaucoma (POAG) and primary angle-closure glaucoma (PACG) in China from 1990 to 2015, with contributing age groups. 


\section{Projection of national population with glaucoma from 2020 to 2050}

In our projection analysis, the age- and gender-specific prevalence estimates of POAG and PACG, and the overall prevalence estimate of secondary glaucoma were all assumed as constant. By applying these estimates to the UNPD data up to the year 2050, the numbers of people with glaucoma were projected (Table S5 in Online Supplementary Document and Table 5). Unlike the slight declining trend of glaucoma prevalence between 1990 and 2015, from 2020 to 2050, the overall prevalence of all glaucoma is expected to increase from $2.64 \%(95 \% \mathrm{CI}=1.99-3.55)$ to $3.48 \%(95 \% \mathrm{CI}=2.63-4.69)$, which is a $32 \%$ increase. For different subtypes of glaucoma, the prevalence of POAG will also increase during this period, but at a lower rate (27\%). In 2020, the prevalence of POAG is projected to be $1.05 \%$ (95\% CI = 0.68 1.60), and then reach $1.33 \%(95 \% \mathrm{CI}=0.86-2.04)$ in 2050. The prevalence of PACG will show a greater increasing rate between 2020 and 2050, from 1.44\% (95\% CI=1.21-1.72) to 2.01\% (95\% CI=1.662.42), ie, by $40 \%$.

The projected number of people living with glaucoma in China is also shown in Table 5. Between 2020 and 2050, the number of all glaucoma cases in China is expected to increase from 15.28 million (95\% $\mathrm{CI}=11.53-20.58)$ to 25.16 million $(95 \% \mathrm{CI}=18.96-33.86)$, ie, by $65 \%$. The increasing rates for POAG and PACG will also be notable within the same period. The number of people with POAG is expected to increase from 6.06 million ( $95 \% \mathrm{CI}=3.95-9.27)$ to 9.59 million (95\% CI=6.23-14.72), and those with PACG from 8.36 million ( $95 \% \mathrm{CI}=7.00-9.98$ ) to 14.49 million ( $95 \% \mathrm{CI}=12.01-17.48$ ), which will translate into the rates of increase between 2020 and 2050 of $58 \%$ and $73 \%$, respectively. Due to the forecasted trend in population ageing over the next three decades, the number of secondary glaucoma cases is anticipated to also increase slightly, from 0.87 million (95\% CI=0.58-1.33) in 2020 to 1.08 million (95\% $\mathrm{CI}=0.72-1.66)$ in 2050; ie, an increase by $24.14 \%$. During this period, PACG will remain the predominant subtype of glaucoma in China, followed by POAG and secondary glaucoma. From 2020 to 2050 , the age group in which most POAG cases will be concentrated will shift from 65-69 years to 75-79 years, and the age group for PACG will shift from 65-69 years to 80-84 years (Figure 6).

\section{Effects of demographic and geographic factors on the prevalence of POAG and PACG}

Based on univariable and multivariable meta-regression models (Table 6), the effects of selected demographic and geographic factors on the risk of POAG and PACG were assessed. The univariable meta-regression indicated that age, gender and study setting were significantly associated with POAG, while PACG was associated with age, gender and geographic region. No evidence for secular trends was observed. After adjusting for age and gender in a multivariable meta-regression, the odds ratio (OR) for each increase in age by 10 years was $1.43(95 \% \mathrm{CI}=1.33-1.55)$ for POAG, and 1.65 (95\% CI=1.51-1.80) for PACG. Males still showed a higher risk of POAG $(1.36,95 \% \mathrm{CI}=1.17-1.59)$, but a lower risk of PACG (0.53, $95 \% \mathrm{CI}=0.46-0.60)$ in comparison with females. People living in urban areas were more likely to have POAG compared to those in rural areas, with an OR of $1.54(95 \% \mathrm{CI}=1.02-2.35)$. Among the six geographic regions, people in Northeast China were at a higher risk $(1.77,95 \% \mathrm{CI}=1.07-2.94)$ of having PACG than people in East China.

Table 5. Projected prevalence and number of people with glaucoma in China from 2020 to 2050, by glaucoma type

\begin{tabular}{|c|c|c|c|c|c|c|}
\hline \multirow[t]{2}{*}{ Glaucoma type } & \multicolumn{2}{|c|}{ Prevalence of glaucoma $(\%, 95 \%$ Cl) } & \multicolumn{2}{|c|}{$\begin{array}{l}\text { NumBer OF PEOPLE WITH GLAUCOMA (MILLION, 95\% } \\
\text { CI) }\end{array}$} & \multicolumn{2}{|c|}{$\begin{array}{l}\text { Relative rate of change (\%, } \\
2020-2050)\end{array}$} \\
\hline & 2020 & 2050 & 2020 & 2050 & Prevalence & Cases \\
\hline \multirow[t]{2}{*}{ POAG } & 1.05 & 1.33 & 6.06 & 9.59 & \multirow[t]{2}{*}{26.67} & \multirow[t]{2}{*}{58.25} \\
\hline & $(0.68-1.60)$ & $(0.86-2.04)$ & $(3.95-9.27)$ & $(6.23-14.72)$ & & \\
\hline \multirow[t]{2}{*}{ PACG } & 1.44 & 2.01 & 8.36 & 14.49 & \multirow[t]{2}{*}{39.58} & \multirow[t]{2}{*}{73.33} \\
\hline & $(1.21-1.72)$ & $(1.66-2.42)$ & $(7.00-9.98)$ & $(12.01-17.48)$ & & \\
\hline \multirow[t]{2}{*}{ Secondary glaucoma } & \multicolumn{2}{|c|}{0.15} & 0.87 & 1.08 & \multirow[t]{2}{*}{-} & \multirow[t]{2}{*}{24.14} \\
\hline & \multicolumn{2}{|c|}{$(0.10-0.23)$} & $(0.58-1.33)$ & $(0.72-1.66)$ & & \\
\hline \multirow[t]{2}{*}{ All glaucoma* } & 2.64 & 3.48 & 15.28 & 25.16 & \multirow[t]{2}{*}{31.82} & \multirow[t]{2}{*}{64.66} \\
\hline & $(1.99-3.55)$ & $(2.63-4.69)$ & (11.53-20.58) & $(18.96-33.86)$ & & \\
\hline
\end{tabular}

POAG - primary open-angle glaucoma, PACG - primary angle-closure glaucoma, CI - confidence interval

*All glaucoma includes both primary glaucoma and secondary glaucoma. 


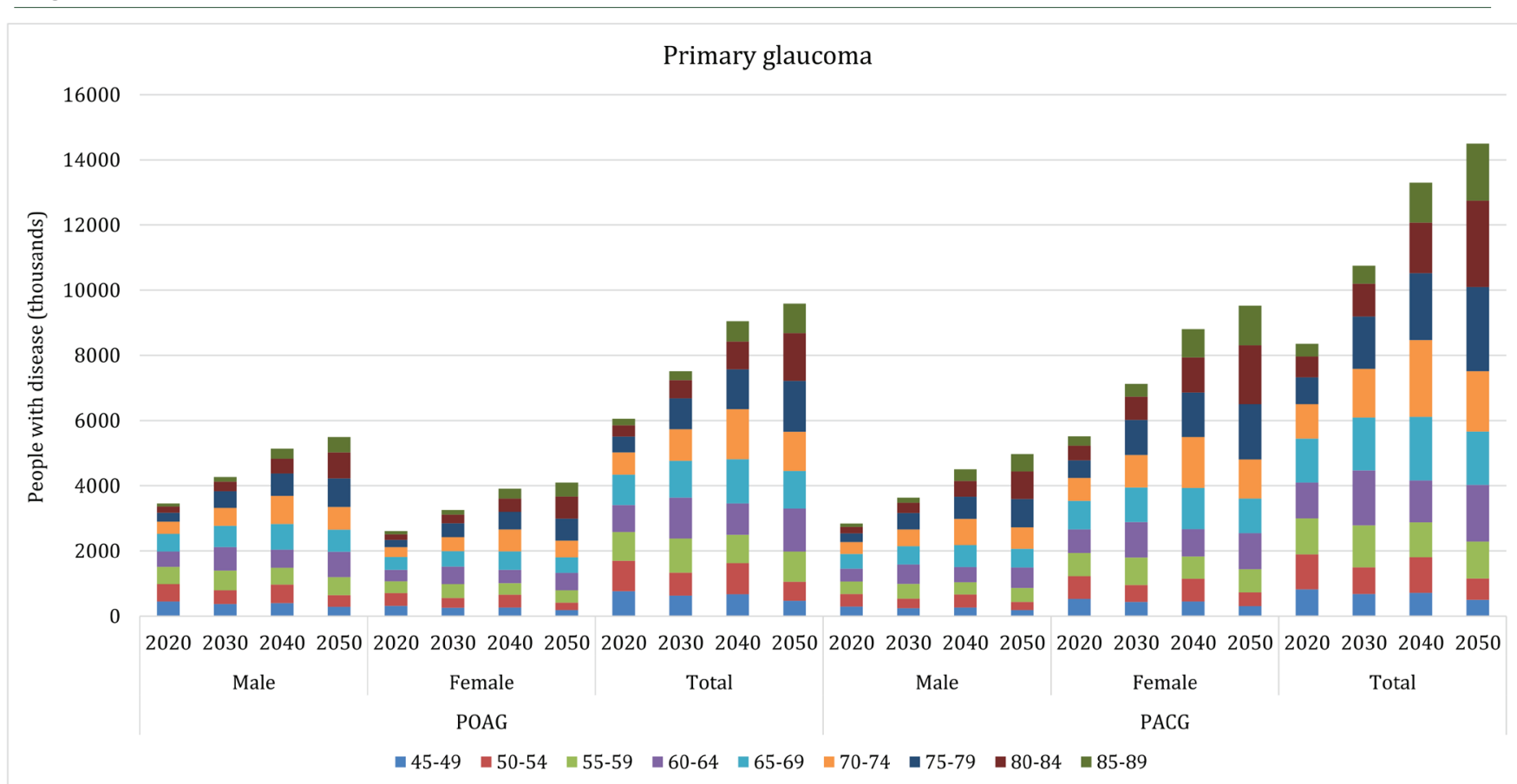

Figure 6. Projected gender-specific number of people with primary open-angle glaucoma (POAG) and primary angle-closure glaucoma (PACG) in China from 2020 to 2050, with contributing age groups.

Table 6. Odds ratios for POAG and PACG in terms of age, gender, setting and geographic region from multilevel univariable and multivariable meta-regression models, with 95\% confidence intervals

\begin{tabular}{|c|c|c|c|c|}
\hline \multirow[t]{2}{*}{ Variabie } & \multicolumn{2}{|c|}{ UnADJUSTED } & \multicolumn{2}{|c|}{ Age And gender-ADJusted } \\
\hline & POAG & PACG & POAG & PACG \\
\hline Age (per decade) & $1.38(1.30-1.47) *$ & $1.58(1.49-1.67)^{*}$ & $1.43(1.33-1.55)^{*}$ & $1.65(1.51-1.80) *$ \\
\hline \multicolumn{5}{|l|}{ Gender: $\dagger$} \\
\hline Female & Reference & Reference & Reference & Reference \\
\hline Male & $1.39(1.19-1.62) *$ & $0.53(0.46-0.60) *$ & $1.36(1.17-1.59) *$ & $0.53(0.46-0.60) *$ \\
\hline \multicolumn{5}{|l|}{ Setting: } \\
\hline Rural & Reference & Reference & Reference & Reference \\
\hline Urban & $1.68(1.13-2.51)^{*}$ & $0.90(0.64-1.28)$ & $1.54(1.02-2.35)^{*}$ & $0.82(0.54-1.23)$ \\
\hline Mixed & $0.93(0.37-2.33)$ & $1.13(0.67-1.90)$ & $2.18(0.68-6.99)$ & $0.64(0.25-1.62)$ \\
\hline \multicolumn{5}{|l|}{ Geographic region: } \\
\hline East & Reference & Reference & Reference & Reference \\
\hline North & $1.44(0.45-4.61)$ & $1.81(0.93-3.52)$ & $1.29(0.36-4.69)$ & $1.23(0.77-1.97)$ \\
\hline Northeast & $1.48(0.31-7.02)$ & $2.87(1.37-6.01)^{*}$ & $1.41(0.26-7.74)$ & $1.77(1.07-2.94) *$ \\
\hline Northwest & $0.80(0.10-6.33)$ & $1.87(0.79-4.41)$ & $0.44(0.05-4.07)$ & $1.38(0.76-2.49)$ \\
\hline South Central & $2.14(0.45-10.14)$ & $1.54(0.72-3.28)$ & - & $0.89(0.51-1.53)$ \\
\hline Southwest & $1.48(0.37-6.00)$ & $1.51(0.69-3.29)$ & $0.94(0.17-5.16)$ & $1.24(0.70-2.22)$ \\
\hline $\begin{array}{l}\text { Investigation year } \\
\text { (per decade) } \ddagger\end{array}$ & $1.07(0.58-1.98)$ & $0.76(0.50-1.15)$ & $1.47(0.51-4.25)$ & $1.18(0.92-1.50)$ \\
\hline
\end{tabular}

\section{Regional population with POAG and PACG from 2000 to 2010}

By taking the effects of age, gender and setting, the national POAG cases were distributed to the six geographic regions in China (Table 7). In 2000, the overall prevalence of POAG was $1.01 \%$ (95\% CI=0.66$1.55)$ in China, ranging from $0.96 \%(95 \% \mathrm{CI}=0.60-1.53)$ in Southwest China to $1.08 \%$ (95\% CI=0.751.54) in Northeast China. In 2010, the overall prevalence of POAG in China rose to $1.03 \%$ (95\% $\mathrm{CI}=0.67-1.57)$, and the regions with the highest prevalence of POAG were Northeast China $(1.05 \%$, 
Table 7. Estimated prevalence and number of people with POAG in China from 2000 to 2010, by geographic region

\begin{tabular}{|c|c|c|c|c|c|c|}
\hline \multirow[t]{2}{*}{ Region } & \multicolumn{2}{|c|}{ Prevalence of POAG $(\%, 95 \%$ CI) } & \multicolumn{2}{|c|}{ NUMBER OF PEOPLE WITH POAG (MILION, 95\% CI) } & \multicolumn{2}{|c|}{$\begin{array}{c}\text { ReLative rate OF CHAMGE } \\
(\%, 2000-2010)\end{array}$} \\
\hline & 2000 & 2010 & 2000 & 2010 & Prevalence & Cases \\
\hline \multirow[t]{2}{*}{ North China } & 1.01 & 1.02 & 0.38 & 0.55 & 1.00 & 46.13 \\
\hline & $(0.67-1.53)$ & $(0.68-1.54)$ & $(0.25-0.57)$ & $(0.37-0.83)$ & & \\
\hline \multirow[t]{2}{*}{ Northeast China } & 1.08 & 1.05 & 0.30 & 0.44 & -2.47 & 45.03 \\
\hline & $(0.75-1.54)$ & $(0.71-1.54)$ & $(0.21-0.43)$ & $(0.30-0.64)$ & & \\
\hline \multirow[t]{2}{*}{ East China } & 1.04 & 1.05 & 1.02 & 1.39 & 1.00 & 36.34 \\
\hline & $(0.69-1.58)$ & $(0.69-1.59)$ & $(0.67-1.54)$ & $(0.91-2.10)$ & & \\
\hline \multirow[t]{2}{*}{ South Central China } & 1.01 & 1.01 & 0.83 & 1.13 & 0.72 & 35.65 \\
\hline & $(0.65-1.56)$ & $(0.65-1.57)$ & $(0.53-1.29)$ & $(0.73-1.75)$ & & \\
\hline \multirow[t]{2}{*}{ Southwest China } & 0.96 & 1.00 & 0.48 & 0.61 & 3.68 & 26.51 \\
\hline & $(0.60-1.53)$ & $(0.63-1.59)$ & $(0.30-0.77)$ & $(0.38-0.97)$ & & \\
\hline \multirow[t]{2}{*}{ Northwest China } & 0.97 & 0.98 & 0.19 & 0.27 & 1.00 & 41.49 \\
\hline & $(0.62-1.51)$ & $(0.62-1.53)$ & $(0.12-0.30)$ & $(0.18-0.43)$ & & \\
\hline \multirow[t]{2}{*}{ China } & 1.01 & 1.03 & 3.21 & 4.39 & 1.05 & 36.97 \\
\hline & $(0.66-1.55)$ & $(0.67-1.57)$ & $(2.09-4.91)$ & $(2.86-6.72)$ & & \\
\hline
\end{tabular}

POAG - primary open-angle glaucoma, PACG - primary angle-closure glaucoma, CI - confidence interval

95\% CI $=0.71-1.54)$ and East China $(1.05 \%, 95 \% \mathrm{CI}=0.69-1.59)$, and that with the lowest POAG prevalence was Northwest China $(0.98 \%, 95 \%$ CI =0.62-1.53). From 2000 to 2010, the prevalence of POAG has risen in China, with an exception of Northeast China, where the prevalence of POAG decreased by $2.47 \%$. The most marked increasing rate was observed in Southwest China (3.68\%). In both 2000 and 2010, the distribution of POAG cases across the six geographic regions was similar, with the most cases in East China and the least in Northwest China. From 2000 to 2010, the greatest increase rate was in North China (46.13\%), and the least in Southwest China (26.51\%).

The number of people with PACG in China was distributed based on the multivariable meta-regression model of PACG and features of the six geographic regions (Table 8). In 2000, the overall prevalence of PACG in China was 1.38\% (95\% CI =1.16-1.65), with the highest regional prevalence estimate in Northeast China (2.04\%, 95\% CI =1.82-2.26) and lowest in South Central China ( $1.12 \%, 95 \% \mathrm{CI}=0.95-1.32)$. In 2010, the national prevalence of PACG rose by $1.30 \%$, reaching to $1.40 \%(95 \% \mathrm{CI}=1.17-1.68)$, and the region with the highest prevalence of PACG was still Northeast China (2.06\%, 95\% CI $=1.84-2.30)$

Table 8. Estimated prevalence and number of people with PACG in China from 2000 to 2010, by geographic region

\begin{tabular}{|c|c|c|c|c|c|c|}
\hline \multirow[t]{2}{*}{ Region } & \multicolumn{2}{|c|}{ Prevalence of PACG $(\%, 95 \%$ CI) } & \multicolumn{2}{|c|}{$\begin{array}{l}\text { NUMBER OF PEOPLE WITH PACG (MILION, 95\% } \\
\text { CI) }\end{array}$} & \multicolumn{2}{|c|}{$\begin{array}{l}\text { RELATIVE RATE OF CHANGE } \\
(\%, 2000-2010)\end{array}$} \\
\hline & 2000 & 2010 & 2000 & 2010 & Prevalence & Cases \\
\hline \multirow[t]{2}{*}{ North China } & 1.48 & 1.47 & 0.55 & 0.79 & -0.47 & 44.00 \\
\hline & $(1.42-1.53)$ & $(1.41-1.52)$ & $(0.53-0.57)$ & $(0.76-0.82)$ & & \\
\hline \multirow[t]{2}{*}{ Northeast China } & 2.04 & 2.06 & 0.57 & 0.86 & 1.27 & 50.59 \\
\hline & $(1.82-2.26)$ & $(1.84-2.30)$ & $(0.51-0.64)$ & $(0.77-0.96)$ & & \\
\hline \multirow[t]{2}{*}{ East China } & 1.27 & 1.27 & 1.24 & 1.68 & -0.03 & 34.94 \\
\hline & $(0.99-1.63)$ & $(0.99-1.63)$ & $(0.97-1.59)$ & $(1.30-2.15)$ & & \\
\hline \multirow[t]{2}{*}{ South Central China } & 1.12 & 1.11 & 0.93 & 1.24 & -0.52 & 33.99 \\
\hline & $(0.95-1.32)$ & $(0.94-1.31)$ & $(0.79-1.09)$ & $(1.05-1.46)$ & & \\
\hline \multirow[t]{2}{*}{ Southwest China } & 1.51 & 1.59 & 0.76 & 0.97 & 5.06 & 28.20 \\
\hline & $(1.22-1.87)$ & $(1.28-1.97)$ & $(0.61-0.94)$ & $(0.78-1.20)$ & & \\
\hline \multirow[t]{2}{*}{ Northwest China } & 1.60 & 1.63 & 0.32 & 0.46 & 1.58 & 42.31 \\
\hline & $(1.26-2.03)$ & $(1.27-2.07)$ & $(0.25-0.41)$ & $(0.36-0.58)$ & & \\
\hline \multirow[t]{2}{*}{ China } & 1.38 & 1.40 & 4.37 & 6.01 & 1.30 & 37.31 \\
\hline & $(1.16-1.65)$ & $(1.17-1.68)$ & $(3.66-5.23)$ & $(5.03-7.18)$ & & \\
\hline
\end{tabular}

POAG - primary open-angle glaucoma, PACG - primary angle-closure glaucoma, CI - confidence interval 
and that with the lowest PACG prevalence was still South Central China (1.11\%, 95\% CI=0.94-1.31). Within this time frame, the prevalence of PACG decreased in North China, East China and South Central China, but increased in Northeast China, Southwest China and Northwest China. The region with the greatest increasing rate of PACG prevalence was Southwest China (5.06\%), and that with the greatest decreasing rate was South Central China (-0.52\%). From 2000 to 2010, East China consistently harboured the largest share of PACG cases, while Northwest China has had the smallest share. Overall, the number of people with PACG increased from 4.37 million (95\% CI=3.66-5.23) to 6.01 million (95\% CI=5.037.18 ), which is a $37 \%$ increase over this period. This increase was also witnessed in every region, being the most marked in Northeast China (51\%) and the least in Southwest China (28\%).

\section{DISCUSSION}

Based on rigorous systematic review of existing evidence on glaucoma prevalence in China, this study offers a comprehensive estimate of the prevalence and burden of glaucoma in China at both national and subnational levels, and compares the relative magnitude of three main subtypes of glaucoma, ie, POAG, PACG and secondary glaucoma, in the general mainland Chinese population. From 1990 to 2015, the prevalence of glaucoma fluctuated at around 2.6\%, corresponding to 5.92 million and 13.12 million people with glaucoma in the years 1990 and 2015, respectively. By 2050, the prevalence of glaucoma will rise to $3.48 \%$, which equivalents to a total of 25.16 million affected people. Substantial evidence demonstrated that PACG was the predominant subtype of glaucoma in the general Chinese population, followed by POAG and secondary glaucoma. The geographic variations in the prevalence of POAG and PACG were also assessed, with urban dwellers at a higher risk of developing POAG than rural dwellers, and people living in Northeast China being more prone to PACG than people in East China. Because of the uneven population distribution in China, from 2000 to 2010, East China consistently had the largest share of both POAG and PACG cases, and Northwest China the least.

To the best of our knowledge, this study is the most up-to-date and comprehensive systematic review and meta-analysis to explore and present the national and subnational prevalence and burden of glaucoma in China. The principal strengths of this study are a reasonable coverage of the Chinese population, a comprehensive literature search, and a stringent approach to selecting studies for inclusion. Ultimately, this systematic review was built upon 30 individuals studies, which was more than double the number of studies included in the first systematic review on glaucoma in China [30]. With a wide geographical scope covering all the six geographic regions of China, the included studies ensured a sufficient power to conduct the estimates for both the whole nation and subnational regions. Furthermore, with the aim of limiting between-study heterogeneity due to methodological variations, the assessments of glaucoma in the studies included were based on structural or functional evidence of glaucomatous optic neuropathy, rather than IOP measurements, which in part guaranteed a very good detection ability of early-stage glaucoma. In addition, POAG in this study included persons with IOP at all levels [3,16]. Moreover, the prevalence and burden of secondary glaucoma in China was developed for the first time, which added new evidence to the epidemiology of glaucoma both domestically and globally.

Despite the strengths of this study, there are also multiple limitations. First, given the diversity of studies included in study design, targeted population, methods and settings, a relatively high degree of heterogeneity among studies included was observed. Although the estimates of POAG and PACG prevalence were generated based on meta-regression, by taking the effects of age, gender and geographic factors together, some factors other than chance may also be attributable to the observed variance, but could not be fully controlled. In this study, a key issue was that we didn't choose to exclude studies based on consensus criteria for the definitions and grading systems of glaucoma, but rather relied on the examinations. This is because previous studies suggested a remarkable similarity among surveys with different survey methods and glaucoma definitions [16,34-36]. This approach for defining eligible studies has been widely adopted in previous systematic reviews on glaucoma prevalence, but it might still be influenced by the inherent subjectivity of interpreting ophthalmic images $[16,17,34,35]$. Second, compared with primary glaucoma, secondary glaucoma has been under-examined in epidemiological studies $[16,17,48]$. In this study, despite our extensive efforts to identify all the available evidence without language restrictions, the number of eligible studies that provided the estimate of secondary glaucoma prevalence was still not sufficient. Given that there was moderate heterogeneity between studies that reported the prevalence of secondary glaucoma, we acknowledge issues about the appropriateness of roughly reporting an overall prevalence of secondary glaucoma. Third, the projections of glaucoma were only based on the assumption 
that the prevalence estimates will be constant, thus, changes in the number of people with glaucoma only reflect changes in demographic features of the next three decades. Although this assumption has been commonly adopted in the projection of disease burden, the power of projection analysis beyond the period of studies conducted is limited $[16,17,49]$. Forth, only the effects of age, gender, setting and geographic region were assessed in subgroup analyses by using both univariable and multivariable meta-regression; however, other relevant factors that were not obtained from the included studies may have also had a role. In addition, all these factors were aggregate level data, thus hampering the opportunity to explore the differences in effects at the individual level, or interaction between factors [50,51]. Fifth, the estimates of glaucoma prevalence were generated at the regional level at best. Any estimates at the provincial level were not possible, owing to the limited availability of data in each province. Taken collectively, the results presented in this study should be interpreted with caution.

The overall estimated prevalence of POAG in this study was slightly higher than that in the previous systematic review (1.0\% vs $0.7 \%$ ) [30]. The disparity between these two estimates might be explained by the combined effect of the different age and gender structures, and the different geographic features of the participants included in these two systematic reviews. Surprisingly, despite the substantial variation in the studies that were included as the basis for both reports, and further differences in adopted methods of meta-analysis, the prevalence of PACG in these two studies was almost identical - both at the level of $1.4 \%$. This similarity in PACG prevalence supports the current understanding of the magnitude of PACG in China.

The prevalence estimates of POAG and PACG were notably associated with advanced age in both sexes; this strong positive relationship matches the natural history of primary glaucoma, which was described in many previous studies. This association confirms the commonly accepted notion that primary glaucoma is an age-related disease [36,52-56]. With increasing longevity, a striking increase in the prevalence and burden of glaucoma is likely, especially for primary glaucoma.

The distribution patterns of POAG and PACG by gender were opposite, with POAG being the predominant subtype of glaucoma in males, and PACG in females. The female predilection for PACG has been widely acknowledged in previous studies, and could be linked to the aetiology of disease, differences in biological factors and environmental exposures between sexes [30,55-58]. However, the evidence of gender effect on POAG is still conflicting $[16,34,35,57]$. The findings in the present study disagree with the first systematic review of glaucoma prevalence in China, where male predilection for POAG was not reported [30]. The discrepancy between these two studies might be explained by the inadequate study power to confirm associations. Further studies are still needed to explore the different effects of gender on the development of glaucoma, especially POAG, and for deciding different public health policies.

In view of the general understanding that secondary glaucoma is caused by other ocular or systematic disorders that may lead to an increase in intraocular pressure, rather than a normal degenerative process with ageing, it was expected that no effects of age, gender or geographic factors would be seen $[48,53]$. Only a pooled overall prevalence was generated for secondary glaucoma, with no separate subgroup analysis. In this study, the prevalence of secondary glaucoma was largely lower than that for East Asia $(0.15 \%$ vs $0.39 \%$ ) [17]. However, this relatively lower prevalence of secondary glaucoma, presented in this study, still needs to be confirmed with new data. There is little doubt that secondary glaucoma is less frequent in comparison with primary glaucoma; however, the disease burden caused by secondary glaucoma should never be underestimated or neglected, bearing in mind its visually destructive effects $[53,54]$.

In China, PACG was estimated to be responsible for the largest share of glaucoma, followed by POAG and secondary glaucoma. This finding confirms previous studies, which concluded that Chinese people might be more likely to develop PACG than any other ethnic groups in the world [36,59]. Mechanisms underlying this phenomenon are controversial, but may be associated with the difference of anterior chamber and angle anatomy among races $[18,60,61]$. In addition, given that PACG is more common in females than males, and females have a longer life expectancy than males, the burden of PACG is considerably concerning [43]. The visual damages of PACG are more severe than of the other main subtypes of glaucoma, presenting an even greater public health challenge with a considerable social and economic impact $[18,21]$.

The higher prevalence of POAG in urban than in rural settings is in agreement with findings from studies conducted in China, and also with many other regions across the world $[16,17,30]$. The reasons for this are not certain, but may be partly related to a higher myopia prevalence in urban areas, and to other potential risk factors for POAG that vary greatly between urban and rural areas. Hypertension, diabetes, diet, 
physical activity and air pollution may also play a role $[16,17,62,63]$. With rapid urbanisation, the prevalence and burden of POAG may continue to increase in China $[64,65]$. For PACG, people in Northeast China had the highest prevalence. An explanation for this geographic variation is an evolutionary modification of shallower anterior chambers that resist corneal freezing $[66,67]$. However, these geographic variations might also be a product of differences in the studies included among regions. Future studies should be undertaken to assess geographical risk factors for glaucoma in more detail, to improve locally relevant policy-making on glaucoma.

The findings of this study add insight to our knowledge of the epidemiology of glaucoma and have clear policy implications for China. Together with an ageing demography, glaucoma, especially primary glaucoma, will place an ever-increasing burden on the already stretched health care services in China, unless proactive preventive strategies are put in place. Despite advances in medical treatment, a cost-effective approach for detecting and diagnosing glaucoma is still lacking [68-71]. Indeed, a strong need remains for the development of an appropriate prevention and treatment framework to counter the growing burden of glaucoma in China, especially in rural and poor areas where medical resources are unevenly distributed. National and local efforts are also needed for the formulation of better medical systems and effective public health strategies informed by evidence, such as reallocating medical resources, improving access to health care, and health education on the importance of early examination.

In the meantime, the need to scale up reliable data on glaucoma epidemiology in places where primary data have never been available has been highlighted in the present study. This is essential for both researchers and policymakers to improve understanding of the magnitude and distribution of this problem and the main risk factors. For a comprehensive assessment of glaucoma epidemiology in China, more robust evidence from studies using consistent methods across populations and further reviews of the prevalence of glaucoma is needed to corroborate the statements in the present study more reliably.

In conclusion, this contemporary systematic review and meta-analysis suggests a substantial burden of glaucoma in China, with considerable variation among the different age groups, genders, study settings and geographic regions. PACG is the predominant subtype of glaucoma in the general Chinese population, followed by POAG and secondary glaucoma. In the next three decades, the prevalence and burden of glaucoma will continue to increase with the current ageing trend. More elaborate epidemiological studies are needed to optimise public health strategies for mitigating this important health problem.

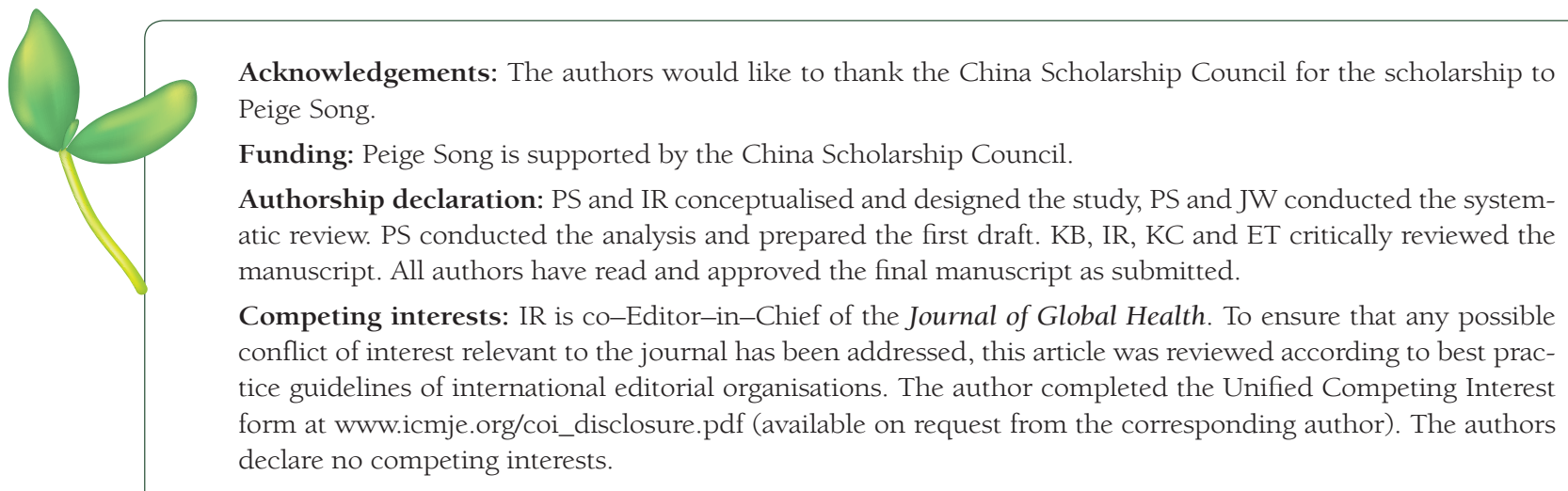

1 Weinreb RN, Aung T, Medeiros FA. The pathophysiology and treatment of glaucoma: a review. JAMA. 2014;311:190111. Medline:24825645 doi:10.1001/jama.2014.3192

2 Weinreb RN, Khaw PT. Primary open-angle glaucoma. Lancet. 2004;363:1711-20. Medline:15158634 doi:10.1016/ S0140-6736(04)16257-0

3 Foster PJ, Buhrmann R, Quigley HA, Johnson GJ. The definition and classification of glaucoma in prevalence surveys. Br J Ophthalmol. 2002;86:238-42. Medline:11815354 doi:10.1136/bjo.86.2.238

4 Congdon NG, Friedman DS. Angle-closure glaucoma: impact, etiology, diagnosis, and treatment. Curr Opin Ophthalmol. 2003;14:70-3. Medline:12698044 doi:10.1097/00055735-200304000-00002

5 Pascolini D, Mariotti SP. Global estimates of visual impairment: 2010. Br J Ophthalmol. 2012;96:614-8. Medline:22133988 doi:10.1136/bjophthalmol-2011-300539 
6 Ramulu P. Glaucoma and disability: which tasks are affected, and at what stage of disease? Curr Opin Ophthalmol. 2009;20:92. Medline:19240541 doi:10.1097/ICU.0b013e32832401a9

7 Rouland J-F, Berdeaux G, Lafuma A. The economic burden of glaucoma and ocular hypertension. Drugs Aging. 2005;22:315-21. Medline:15839720 doi:10.2165/00002512-200522040-00004

8 Varma R, Lee PP, Goldberg I, Kotak S. An assessment of the health and economic burdens of glaucoma. Am J Ophthalmol. 2011;152:515-22. Medline:21961848 doi:10.1016/j.ajo.2011.06.004

9 Traverso CE, Walt J, Kelly S, Hommer A, Bron A, Denis P, et al. Direct costs of glaucoma and severity of the disease: a multinational long term study of resource utilisation in Europe. Br J Ophthalmol. 2005;89:1245-9. Medline:16170109 doi:10.1136/bjo.2005.067355

10 Quigley HA. Number of people with glaucoma worldwide. Br J Ophthalmol. 1996;80:389-93. Medline:8695555 doi:10.1136/bjo.80.5.389

11 Topouzis F, Coleman AL, Harris A, Koskosas A, Founti P, Gong G, et al. Factors associated with undiagnosed open-angle glaucoma: the Thessaloniki Eye Study. Am J Ophthalmol. 2008;145:327-35. Medline:18045565 doi:10.1016/j. ajo.2007.09.013

12 Nduaguba C, Lee RK. Glaucoma screening: current trends, economic issues, technology, and challenges. Curr Opin Ophthalmol. 2006;17:142-52. Medline:16552249 doi:10.1097/01.icu.0000193088.75432.c9

13 Rulli E, Biagioli E, Riva I, Gambirasio G, De Simone I, Floriani I, et al. Efficacy and safety of trabeculectomy vs nonpenetrating surgical procedures: a systematic review and meta-analysis. JAMA Ophthalmol. 2013;131:1573-82. Medline:24158640 doi:10.1001/jamaophthalmol.2013.5059

14 Schwartz GF. Compliance and persistency in glaucoma follow-up treatment. Curr Opin Ophthalmol. 2005;16:114-21. Medline:15744142 doi:10.1097/01.icu.0000156139.05323.26

15 Quigley HA, Broman AT. The number of people with glaucoma worldwide in 2010 and 2020. Br J Ophthalmol. 2006;90:262-7. Medline:16488940 doi:10.1136/bjo.2005.081224

16 Tham Y-C, Li X, Wong TY, Quigley HA, Aung T, Cheng C-Y. Global prevalence of glaucoma and projections of glaucoma burden through 2040: a systematic review and meta-analysis. Ophthalmology. 2014;121:2081-90. Medline:24974815 doi:10.1016/j.ophtha.2014.05.013

17 Chan EW, Li X, Tham Y-C, Liao J, Wong TY, Aung T, et al. Glaucoma in Asia: regional prevalence variations and future projections. Br J Ophthalmol. 2016;100:78-85. Medline:26112871 doi:10.1136/bjophthalmol-2014-306102

18 Wong TY, Loon S, Saw S. The epidemiology of age related eye diseases in Asia. Br J Ophthalmol. 2006;90:506-11. Medline:16547337 doi:10.1136/bjo.2005.083733

19 United Nations. World population ageing 2015. New York: Department of Economic and Social Affairs, United Nations; 2015.

20 Shetty P. Grey matter: ageing in developing countries. Lancet. 2012;379:1285-7. Medline:22489326 doi:10.1016/S01406736(12)60541-8

21 Foster PJ, Johnson GJ. Glaucoma in China: how big is the problem? Br J Ophthalmol. 2001;85:1277-82. Medline:11673287 doi:10.1136/bjo.85.11.1277

22 World Health Organization. World report on ageing and health. Geneva: World Health Organization; 2015.

23 Woo J, Kwok T, Sze F, Yuan H. Ageing in China: health and social consequences and responses. Int J Epidemiol. 2002;31:772-5. Medline:12177017 doi:10.1093/ije/31.4.772

24 Xia J, Wright J, Adams CE. Five large Chinese biomedical bibliographic databases: accessibility and coverage. Health Info Libr J. 2008;25:55-61. Medline:18251914 doi:10.1111/j.1471-1842.2007.00734.x

25 Fung IC. Chinese journals: a guide for epidemiologists. Emerg Themes Epidemiol. 2008;5:20. Medline:18826604 doi:10.1186/1742-7622-5-20

26 Song P, Theodoratou E, Li X, Liu L, Chu Y, Black RE, et al. Causes of death in children younger than five years in China in 2015: an updated analysis. J Glob Health. 2016;6:020802. Medline:28028436 doi:10.7189/jogh.06.020802

27 Wang YX, Xu L, Yang H, Jonas JB. Prevalence of glaucoma in North China: the Beijing eye study. Am J Ophthalmol. 2010;150:917-24. Medline:20970107 doi:10.1016/j.ajo.2010.06.037

28 Song W, Shan L, Cheng F, Fan P, Zhang L, Qu W, et al. Prevalence of glaucoma in a rural northern China adult population: a population-based survey in Kailu County, Inner Mongolia. Ophthalmology. 2011;118:1982-8. Medline:21684607 doi:10.1016/j.ophtha.2011.02.050

29 Sun J, Zhou X, Kang Y, Yan L, Sun X, Sui H, et al. Prevalence and risk factors for primary open-angle glaucoma in a rural northeast China population: a population-based survey in Bin County, Harbin. Eye (Lond). 2012;26:283. Medline:22157917 doi:10.1038/eye.2011.243

30 Cheng J-W, Cheng S-W, Ma X-Y, Cai J-P, Li Y, Wei R-L. The prevalence of primary glaucoma in mainland China: a systematic review and meta-analysis. J Glaucoma. 2013;22:301-6. Medline:22134352 doi:10.1097/IJG.0b013e31824083ca

31 Moher D, Liberati A, Tetzlaff J, Altman DG. Preferred reporting items for systematic reviews and meta-analyses: the PRISMA statement. Ann Intern Med. 2009;151:264-9. Medline:19622511 doi:10.7326/0003-4819-151-4-200908180-00135

32 Stevens GA, Alkema L, Black RE, Boerma JT, Collins GS, Ezzati M, et al. Guidelines for accurate and transparent health estimates reporting: the GATHER statement. PLoS Med. 2016;13:e1002056. Medline:27351744 doi:10.1371/journal. pmed.1002056

33 Quigley HA, West SK, Munoz B, Mmbaga B, Glovinsky Y. Examination methods for glaucoma prevalence surveys. Arch Ophthalmol. 1993;111:1409-15. Medline:8216023 doi:10.1001/archopht.1993.01090100117038 
34 Rudnicka AR, Mt-Isa S, Owen CG, Cook DG, Ashby D. Variations in primary open-angle glaucoma prevalence by age, gender, and race: a Bayesian meta-analysis. Invest Ophthalmol Vis Sci. 2006;47:4254-61. Medline:17003413 doi:10.1167/ iovs.06-0299

35 Kapetanakis VV, Chan MP, Foster PJ, Cook DG, Owen CG, Rudnicka AR. Global variations and time trends in the prevalence of primary open angle glaucoma (POAG): a systematic review and meta-analysis. Br J Ophthalmol. 2016;100:8693. Medline:26286821 doi:10.1136/bjophthalmol-2015-307223

36 Friedman DS, Wolfs RC, O'Colmain BJ, Klein BE, Taylor HR, West S, et al; Eye Diseases Prevalence Research Group. Prevalence of open-angle glaucoma among adults in the United States. Arch Ophthalmol. 2004;122:532. Medline:15078671 doi:10.1001/archopht.122.4.532

37 National Bureau of Statistics. Tabulation on the 2000 population census of the People's Republic of China. Beijing: China Statistics Press; 2002.

38 National Bureau of Statistics. Tabulation on the 2010 population census of the People's Republic of China. Beijing: China Statistics Press; 2012.

39 Barendregt JJ, Doi SA, Lee YY, Norman RE, Vos T. Meta-analysis of prevalence. J Epidemiol Community Health. 2013;67:974-8. Medline:23963506 doi:10.1136/jech-2013-203104

40 Higgins JP, Green S. Cochrane handbook for systematic reviews of interventions. Vol 5: Wiley Online Library; 2008.

41 Hox JJ, Moerbeek M, van de Schoot R. Multilevel analysis: Techniques and applications. Routledge; 2010.

42 Viechtbauer W. Conducting meta-analyses in R with the metafor package. J Stat Softw. 2010;36:1-48. doi:10.18637/jss. v036.i03

43 United Nations, Department of Economic and Social Affairs, Population Division. World Population Prospects, the 2015 Revision. 2015. Available: https://esa.un.org/unpd/wpp/. Accessed: 8 January 2017.

44 Vittinghoff E, McCulloch CE. Relaxing the rule of ten events per variable in logistic and Cox regression. Am J Epidemiol. 2007;165:710-8. Medline:17182981 doi:10.1093/aje/kwk052

45 Rudan I, Tomaskovic L, Boschi-Pinto C, Campbell H. Global estimate of the incidence of clinical pneumonia among children under five years of age. Bull World Health Organ. 2004;82:895-903. Medline:15654403

46 Fowkes FGR, Rudan D, Rudan I, Aboyans V, Denenberg JO, McDermott MM, et al. Comparison of global estimates of prevalence and risk factors for peripheral artery disease in 2000 and 2010: a systematic review and analysis. Lancet. 2013;382:1329-40. Medline:23915883 doi:10.1016/S0140-6736(13)61249-0

47 Adeloye D, Chua S, Lee C, Basquill C, Papana A, Theodoratou E, et al. Global and regional estimates of COPD prevalence: Systematic review and meta-analysis. J Glob Health. 2015;5:020415. Medline:26755942 doi:10.7189/ jogh.05.020415

48 Yamamoto T, Iwase A, Araie M, Suzuki Y, Abe H, Shirato S, et al. The Tajimi Study report 2: prevalence of primary angle closure and secondary glaucoma in a Japanese population. Ophthalmology. 2005;112:1661-9. Medline:16111758 doi:10.1016/j.ophtha.2005.05.012

49 Wong WL, Su X, Li X, Cheung CMG, Klein R, Cheng C-Y, et al. Global prevalence of age-related macular degeneration and disease burden projection for 2020 and 2040: a systematic review and meta-analysis. Lancet Glob Health. 2014;2:e106-16. Medline:25104651 doi:10.1016/S2214-109X(13)70145-1

50 Welch VA, Ghogomu E, Hossain A, Awasthi S, Bhutta ZA, Cumberbatch C, et al. Mass deworming to improve developmental health and wellbeing of children in low-income and middle-income countries: a systematic review and network meta-analysis. Lancet Glob Health. 2017;5:e40-50. Medline:27955788 doi:10.1016/S2214-109X(16)30242-X

51 Song P, Chang X, Wang M, An L. Variations of pterygium prevalence by age, gender and geographic characteristics in China: A systematic review and meta-analysis. PLoS One. 2017;12:e0174587. Medline:28355301 doi:10.1371/journal. pone. 0174587

52 Gabelt BT, Kaufman PL. Changes in aqueous humor dynamics with age and glaucoma. Prog Retin Eye Res. 2005;24:61237. Medline:15919228 doi:10.1016/j.preteyeres.2004.10.003

53 Quigley HA. Glaucoma. Lancet. 2011;377:1367-77. Medline:21453963 doi:10.1016/S0140-6736(10)61423-7

54 Foster PJ, Oen FT, Machin D, Ng T-P, Devereux JG, Johnson GJ, et al. The prevalence of glaucoma in Chinese residents of Singapore: a cross-sectional population survey of the Tanjong Pagar district. Arch Ophthalmol. 2000;118:1105-11. Medline:10922206 doi:10.1001/archopht.118.8.1105

55 Friedman DS, Gazzard G, Min CB, Broman AT, Quigley H, Tielsch J, et al. Age and sex variation in angle findings among normal Chinese subjects: a comparison of UBM, Scheimpflug, and gonioscopic assessment of the anterior chamber angle. J Glaucoma. 2008;17:5-10. Medline:18303376 doi:10.1097/IJG.0b013e31806ab327

56 Xu L, Cao WF, Wang YX, Chen CX, Jonas JB. Anterior chamber depth and chamber angle and their associations with ocular and general parameters: the Beijing Eye Study. Am J Ophthalmol. 2008;145:929-36. Medline:18336789 doi:10.1016/j.ajo.2008.01.004

57 Vajaranant TS, Nayak S, Wilensky JT, Joslin CE. Gender and glaucoma: what we know and what we need to know. Curr Opin Ophthalmol. 2010;21:91. Medline:20051857 doi:10.1097/ICU.0b013e3283360b7e

58 Cheng J-W, Zong Y, Zeng Y-Y, Wei R-L. The prevalence of primary angle closure glaucoma in adult Asians: a systematic review and meta-analysis. PLoS One. 2014;9:e103222. Medline:25057993 doi:10.1371/journal.pone.0103222

59 He M, Foster P, Johnson G, Khaw P. Angle-closure glaucoma in East Asian and European people. Different diseases? Eye (Lond). 2006;20:3-12. Medline:15688051 doi:10.1038/sj.eye.6701797

60 Congdon NG, Foster P, Wamsley S, Gutmark J, Nolan W, Seah S, et al. Biometric gonioscopy and the effects of age, race, and sex on the anterior chamber angle. Br J Ophthalmol. 2002;86:18-22. Medline:11801496 doi:10.1136/bjo.86.1.18 
61 Leung CK, Palmiero P, Weinreb R, Li H, Sbeity Z, Dorairaj S, et al. Comparisons of anterior segment biometry between Chinese and Caucasians using anterior segment optical coherence tomography. Br J Ophthalmol. 2010;94:1184-9. Medline:20610476 doi:10.1136/bjo.2009.167296

62 Kwon YH, Fingert JH, Kuehn MH, Alward WL. Primary open-angle glaucoma. N Engl J Med. 2009;360:1113-24. Medline:19279343 doi:10.1056/NEJMra0804630

63 Bonovas S, Peponis V, Filioussi K. Diabetes mellitus as a risk factor for primary open-angle glaucoma: a meta-analysis. Diabet Med. 2004;21:609-14. Medline:15154948 doi:10.1111/j.1464-5491.2004.01173.x

64 Gong P, Liang S, Carlton EJ, Jiang Q, Wu J, Wang L, et al. Urbanisation and health in China. Lancet. 2012;379:843-52. Medline:22386037 doi:10.1016/S0140-6736(11)61878-3

65 Zhang KH, Shunfeng S. Rural-urban migration and urbanization in China: Evidence from time-series and cross-section analyses. China Econ Rev. 2003;14:386-400. doi:10.1016/j.chieco.2003.09.018

66 Qu W, Li Y, Song W, Zhou X, Kang Y, Yan L, et al. Prevalence and risk factors for angle-closure disease in a rural Northeast China population: a population-based survey in Bin County, Harbin. Acta Ophthalmol. 2011;89:e515-20. Medline:21834920 doi:10.1111/j.1755-3768.2011.02146.x

67 Casson RJ, Newland H, Muecke J, McGovern S, Abraham L, Shein W, et al. Gonioscopy findings and prevalence of occludable angles in a Burmese population: the Meiktila Eye Study. Br J Ophthalmol. 2007;91:856-9. Medline:17576708 doi:10.1136/bjo.2006.108688

68 Barton K, Hitchings RA. Medical management of glaucoma. Springer; 2013:71-100.

69 Hernández R, Rabindranath K, Fraser C, Vale L, Blanco AA, Burr JM. Screening for open angle glaucoma: systematic review of cost-effectiveness studies. J Glaucoma. 2008;17:159-68. Medline:18414099 doi:10.1097/IJG.0b013e31814b9693

70 Hernández RA, Burr JM, Vale LD. Economic evaluation of screening for open-angle glaucoma. Int J Technol Assess Health Care. 2008;24:203-11. Medline:18400124 doi:10.1017/S0266462308080288

71 Vaahtoranta-Lehtonen H, Tuulonen A, Aronen P, Sintonen H, Suoranta L, Kovanen N, et al. Cost effectiveness and cost utility of an organized screening programme for glaucoma. Acta Ophthalmol Scand. 2007;85:508-18. Medline:17655612 doi:10.1111/j.1755-3768.2007.00947.x 